\title{
Grain yield and associated photosynthesis characteristics during dryland winter wheat cultivar replacement since 1940 on the Loess Plateau as affected by seeding rate
}

\author{
Yingying Sun 1,2,3, Xiaojuan Yan1, Suiqi Zhang1,4*, Nan Wang1,4 \\ ${ }^{1}$ State Key Laboratory of Soil Erosion and Dryland Farming on the Loess Plateau, Northwest A\&F University, Yangling 712100, China, \\ ${ }^{2}$ Shaanxi Provincial Land Engineering Construction Group Company Limited, Shaanxi Province Land Reclamation Engineering Technology \\ Research Center, Xi'an 710075, China, ${ }^{3}$ Key Laboratory of Degraded and Unused Land Consolidation Engineering, the Ministry of Land and \\ Resources of China, Xi'an 710075, China, ${ }^{4}$ State Key Laboratory of Soil Erosion and Dryland Farming on the Loess Plateau, Institute of Soil \\ and Water Conservation, Chinese Academy of Sciences and Ministry of Water Resources, Yangling 712100, China
}

\section{A B S T R A C T}

An experiment was conducted to verify how the grain yield and associated photosynthesis characteristics of wheat respond to seeding rate with cultivar replacement. Seven wheat cultivars released from 1940 to 2004 that were once widely grown on the Loess Plateau were grown in field experiments during the 2011-2012 growing season at the Changwu experiment station in China using three seeding rates $\left(100,250\right.$, and 350 seeds $\left.\mathrm{m}^{-2}\right)$, using a randomized complete block with a split-plot design and three blocks. The grain yield increased linearly with cultivar development in all seeding rate treatments, with annual genetic gains ranging from $0.65 \%$ to $1.29 \%$. The cultivars released after the 1980 s were less sensitive to seeding rate and had better population regulation. The improvements in the harvest index and thousand grain weights of the modern cultivars were significantly and positively correlated with the grain yield. The photosynthetic rate of the flag leaf and the leaf area index at anthesis consistently increased with cultivar replacement, contributing more to the thousandgrain weight and resulting in grain yield increases. Diffuse non-interceptance at anthesis resulted in opposite, stable trends with time. One reason to adapt modern cultivars for modern cultivation is their lower sensitivity to seeding rate. Thus, larger sinks for the grains and the optimization of plant types for light interception should be given greater consideration in dryland wheat breeding on the Loess Plateau.

Keywords: Dryland wheat; Genetic gain; Seeding density; Light interception ability

\section{INTRODUCTION}

Wheat (Triticum aestivum L.) grain yields have doubled in the last century (Richards, 2000), with the development of genetic resources accounting for more than $40 \%$ of this increase (Brancourt-Hulmel et al., 2003). Genetic progress regarding the grain yield, agronomic traits and photosynthetic traits of wheat has been studied in many countries (e.g., in the UK (Austin et al., 1980), Mexico (Fischer and Edmeades, 2010), Canada (McCaig and DePauw, 1995), Argentina (Maydup et al., 2012), Australia (Potgieter et al., 2016), and China (Tian et al., 2011; Zheng et al., 2011). These studies suggest that cultivar replacement has increased the leaf area index and the net photosynthetic rate (per-unit leaf area) (Fischer and Edmeades, 2010; Tian et al., 2011), which are correlated with greater grain weights and harvest index (HI) values and result in genetic yield improvements (Austin et al., 1980; Perry and D'Antuono, 1989). Different results from the USA (Gent and Kiyomoto, 1985) have indicated that the photosynthetic capacity has remained stable despite cultivar replacement. Verifying the evolution of agronomic traits and the physiological basis of grain yields will assist breeders and agronomists in developing new wheat cultivars with stable and high yields.

The population size significantly influenced the yield performance of winter wheat due to changes in individual

\footnotetext{
${ }^{*}$ Corresponding author:

Suiqi Zhang, State Key Laboratory of Soil Erosion and Dryland Farming on the Loess Plateau, Institute of Soil and Water Conservation, Chinese Academy of Sciences and Ministry of Water Resources, Yangling 712100, China. E-mail: sqzhang@ms.iswc.ac.cn
}

Received: 01 August 2016; Revised: 10 December 2016; Accepted: 18 December 2016; Published Online: 02 January 2017 
growth (Gooding et al., 2002) and lodging (Easson et al., 1993). No marked differences are reported among varieties regarding the responses of grain yields to variations in plant density (Arduini et al., 2006; Brian et al., 2011). However, Black and Aase (1982) reported that USSR winter wheat cultivars were more capable of maintaining a high number of kernels per spike at a high plant density than USA cultivars. According to Marshall and Ohm (1987) and Anderson and Barclay (1991), optimal plant populations change according to their variety and local conditions. In Italy, narrow row spacings of between 12 and $18 \mathrm{~cm}$ and seeding densities of approximately 400 seeds $\mathrm{m}^{-2}$ are traditionally used for wheat (Arduini et al., 2006). In contrast, densities of approximately 250 seeds $\mathrm{m}^{-2}$ or less are considered optimal in the USA and China (Carr et al., 2003; Fang et al., 2010). The response of grain yields to seeding rate with cultivar replacement requires further research.

At least six wheat cultivar replacements have been grown on the Loess Plateau since 1940s (Chen et al., 2003). Although increases in production slowed in the early 2000s (Zhang et al., 2009), significant genetic gains have been observed (Chen et al., 2003). According to a previous study in this region, greater wheat yields were strongly and positively correlated with increasing grain weights, which resulted from an increased filling rate (Zhang et al., 2008). The photosynthetic capacity per unit of leaf area after elongation is also an important source of this progress (Chen et al., 2012). Although different cultivars might vary differently when different seeding rates are used, it has not been considered.

Thus, seven cultivars released since 1940 were studied using different seeding rates (1) to explore the evolution of wheat grain yields and agronomic traits with their responses to seeding rate and (2) to identify the correlations between photosynthetic characteristics and yield progress under different seeding rates.

\section{MATERIALS AND METHODS}

\section{Plant materials, growth conditions and meteorological conditions}

Seven wheat cultivars released from 1940 to 2004 and once planted on the Loess Plateau (Table 1) were used. Field experiments were conducted on the Loess Plateau in Changwu $\left(107^{\circ} 40^{\prime}\right.$ to $107^{\circ} 42 \mathrm{E}, 35^{\circ} 12^{\prime}$ to $35^{\circ} 16^{\prime} \mathrm{N}$, $1200 \mathrm{~m}$ asl), Shaanxi Province, China, during the growing season from 2011 to 2012. The site was located in a semihumid area of the Loess Plateau, where rain-fed cropping with one harvest per year is standard practice. The soil is a dark loessial soil locally classified as a Heilu soil. The average annual precipitation (rain and snow) in the area is $584 \mathrm{~mm}$, and mainly occurs from July to September. The precipitation during the experimental year (Fig. 1) was recorded at an automated meteorological station on the site. In the experimental year, the total precipitation was $388.4 \mathrm{~mm}$ during the fallow period (July-September) and $278.4 \mathrm{~mm}$ during the growing season (September-June of the next year).

\section{Experimental design}

The experiment was conducted using a randomized complete block with a split-plot design and three blocks, and the plot size was $12 \mathrm{~m}^{2}$ (14 rows, $4 \mathrm{~m}$ long and $20 \mathrm{~cm}$ row spacing). The main plots consisted of the different seeding rates [low: 100 seeds $\mathrm{m}^{-2}$, medium: 250 seeds $\mathrm{m}^{-2}$ (the value adopt by the local farmers), and high: 350 seeds $\mathrm{m}^{-2}$. The subplots consisted of the seven cultivars used (Table 1). Fertilizer was applied [urea (N) $150 \mathrm{~kg} \mathrm{ha}^{-1}$ and calcium superphosphate $\left.\left(\mathrm{P}_{2} \mathrm{O}_{5}\right) 120 \mathrm{~kg} \mathrm{ha}^{-1}\right]$ before planting, and no additional fertilizer was applied before harvest. Fungicides and pesticides were applied in each treatment at the shooting and grain filling stages to prevent attack by diseases and pests.

\section{Plant sampling and observations}

At maturity, four central rows (1 $\mathrm{m}$ long) were harvested, air-dried and weighed to determine the total aboveground biomass, grain yield and grain number per $\mathrm{m}^{2}$. Subsamples were used to record the height, grain number per spike and thousand-grain weight (TGW).

The photosynthetic traits were recorded 3 days after flowering. The photosynthetic rate (Pn) of the flag leaf was measured between 9:30 and 11:30 AM using a LI-6400 portable photosynthesis system (LI-COR Inc., Lincoln, NE, USA) in every plot. These measurements were performed approximately halfway along the length of the flag leaf, which was exposed to full sunlight. The Pn values were calculated as the sum of the mean readings for five leaves per plot. The canopy characteristics were recorded using an LAI-2200 Plant Canopy Analyzer (LI-COR Inc., Lincoln, NE, USA) without direct sunlight. One above-canopy measurement and three below-canopy measurements at the soil surface were taken in each plot. The leaf area index (LAI), mean tilt angle (MTA) and diffuse non-interceptance (DIFN) were measured.

\section{Statistical analyses}

Analysis of variance tests were conducted using SAS V8.0 (SAS Institute, Inc., University of Texas, Arlington) and the mono factor analysis of variance method. Linear correlations between the phenotypic traits and the yield 
Table 1: Representative cultivars of dryland winter wheat on the Loess Plateau from 1940 to 2004

\begin{tabular}{|c|c|c|c|c|c|}
\hline Cultivars & $\begin{array}{l}\text { Planting decade on } \\
\text { the Loess Plateau }\end{array}$ & $\begin{array}{l}\text { Year of } \\
\text { release }\end{array}$ & Pedigree & Breeding sites & Dwarf genes \\
\hline Mazha & 1940s & 1940 & Landrace & Shaanxi Province & none \\
\hline Bima1 & $1950 \mathrm{~s}$ & 1951 & Mazha/Biyu & Shaanxi Province & none \\
\hline Fengchan3 & $1960 s$ & 1964 & Danmai 1/Xinong 6028×Bima1 & Shaanxi Province & none \\
\hline Hanxuan 10 & $1970 s$ & 1966 & Nongda 16/Huabei 187 & Shanxi Province & none \\
\hline Xiaoyan6 & $1980 s$ & 1981 & $(\mathrm{ST} 2422 \times 464) /$ Xiaoyan96 & Shaanxi Province & $R h t-B 1 b+R h t 8$ \\
\hline Changwu134 & $1990 \mathrm{~s}$ & 1997 & $\begin{array}{l}\text { (Changwu131×Xiaohei96) F1/Changwu131) } \\
\text { F4/(Jinghua3/NS2761) F1 }\end{array}$ & Shaanxi Province & $R h t-B 1 b$ \\
\hline Changhan58 & $2000 s$ & 2004 & Changwu112/PH 82-2 & Shaanxi Province & $R h t-B 1 b$ \\
\hline
\end{tabular}

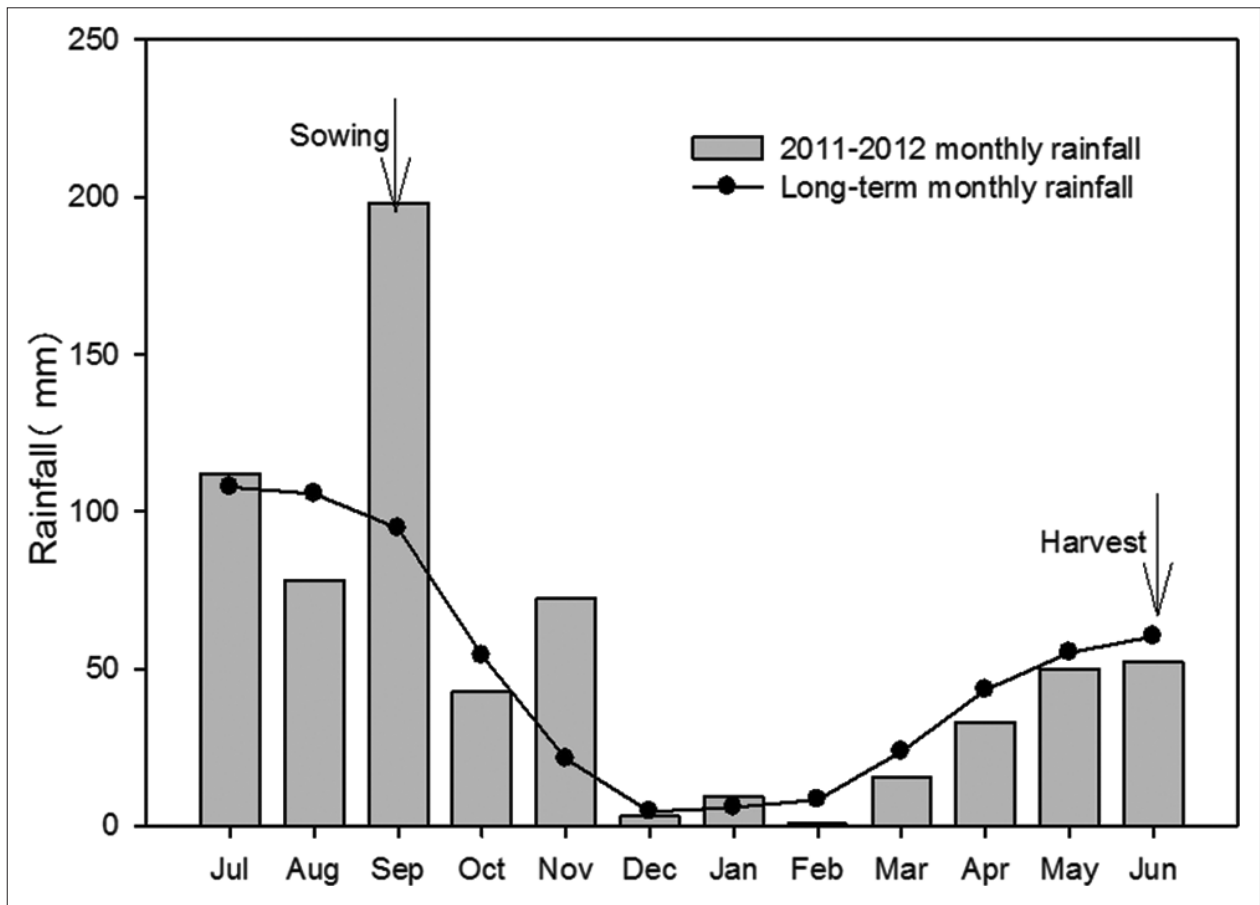

Fig 1. Monthly precipitation from July 2011 to June 2012 compared with the long-term monthly means (1956-2008) at the experimental site.

elements were determined using Pearson's test in the SPSS 19.0 software (IBM, Armonk, New York).

The absolute (1) (grain yield gains in mega-grams per hectare per year) or exponential (2) (the percentage grain yield gain per year) genetic gains of the grain yield and the related traits were modeled using the following equation:

$y i=\mathrm{a}+\mathrm{b} x i+\mathrm{u}$

or $\ln (y z)=\mathrm{a}+\mathrm{b} x i+\mathrm{u}$

Where $y i$ is the estimated mean grain yield in each trial of cultivar $\mathrm{i}, \ln (y i)$ is the natural $\log$ of $y i$, and $x \mathrm{i}$ is the year in which cultivar $i$ was released. The intercepts of both equations were estimated by a, and the slope (b) was used to measure the absolute or exponential grain yield gains (percent). The residual error was estimated by u (OrtizMonasterio et al., 1997).

\section{RESULTS}

Genetic improvements in yield with different seeding rates

Consistent genetic gains were achieved for every seeding rate during the growing season (Table 2), with the medium rate producing the highest genetic gain $\left(1.29 \%, \mathrm{R}^{2}=0.81\right.$, $\mathrm{P}<0.01$ ). The medium seeding rate (local farmers' selection) was always the best seeding rate, and only the cultivar from 2004 resulted in a greater yield as the seeding rate increased. The coefficient of variation (CV) significantly decreased with cultivar replacement.

\section{Contributions of agronomic traits to yield and genetic improvements}

The plant height at maturity decreased significantly with cultivar replacement $\left(\mathrm{R}_{\text {Low }}^{2}=0.76, \mathrm{P}<0.05 ; \mathrm{R}_{\text {Medium }}^{2}=0.82\right.$, $\mathrm{P}<0.01 ; \mathrm{R}_{\text {High }}^{2}=0.84, \mathrm{P}<0.01$, respectively) in every 
Table 2: Yields of the seven cultivars grown at different seeding rates

\begin{tabular}{|c|c|c|c|c|}
\hline Yield $\left(\right.$ kg ha $\left.^{-1}\right)$ & Low seeding rate & Medium seeding rate & High seeding rate & CV (\%) \\
\hline 1940 & $4043 b^{\dagger}$ & $5210 a$ & $3533 b$ & 20 \\
\hline 1951 & $4413 b$ & $6023 a$ & $4270 b$ & 20 \\
\hline 1964 & $6590 a$ & $5593 a b$ & $4970 b$ & 14 \\
\hline 1966 & $4160 b$ & $5243 a$ & $3873 b$ & 16 \\
\hline 1981 & $5833 b$ & $6690 a$ & $5093 b$ & 14 \\
\hline 1997 & $6860 a b$ & $7250 a$ & $6320 b$ & 7 \\
\hline 2004 & $7166 c$ & $8183 b$ & $9496 a$ & 14 \\
\hline Genetic gain (\%) & 0.65 & 1.29 & 0.93 & -1.15 \\
\hline $\mathrm{R}^{2}$ & $0.79^{*}$ & $0.81^{* *}$ & $0.83^{*}$ & $0.56^{*}$ \\
\hline SE & 511 & 422 & 771 & 0.137 \\
\hline
\end{tabular}

${ }^{\dagger}$ Means followed by the same letters within the same column were not significantly different between the different seeding rates at $\mathrm{P}=0.05$. ${ }^{\star}$ Significant at $\mathrm{P}=0.05$, ** Significant at $\mathrm{P}=0.01$

treatment (Fig. 2) because of the introduced dwarf genes (Table 1). In each seeding rate treatment, the aboveground biomass, spike number, grain number per spike and grain number per unit area were almost stable with cultivar replacement. However, the HI and TGW increased significantly (Table 3 ). In the supplementation treatments, the yields of the modern cultivars improved as the HI and TGW increased and were less correlated with the aboveground biomass and grain number (Table 4). However, these results were not always consistent. In the low seeding rate treatment, the aboveground biomass played an important role in the genetic gain $(\mathrm{r}=0.80$, $\mathrm{P}<0.01)$ and in the grain number per unit area $(\mathrm{r}=0.65$, $\mathrm{P}>0.05)$.

\section{Photosynthetic characteristic variations at anthesis and their relationship with yield improvement under different seeding rates}

The Pn of the flag leaf peaked at the low seeding rate for all cultivars. However, no significant differences were observed between the medium seeding rate and the high seeding rate (Fig. 3). At the low seeding rate, the Pn of the flag leaves significantly increased with cultivar replacement $\left(\mathrm{R}^{2}=0.74, \mathrm{P}<0.05\right)$. In contrast, this increase was small for the other seeding densities (Fig. 3a). The $\mathrm{N}$ contents of the flag leaves were consistent with the Pn (Fig. 3b). However, when the 1966 cultivar was excluded from the analysis, the Pn significantly increased over the decades when using medium and high seeding rates.

The canopy characteristics of all cultivars at anthesis among the different seeding rates were consistent (Fig. 4). The MTA at anthesis showed no evident difference among cultivars (Fig. 4b). However, when excluding the cultivar that was released in 1966, which had an extremely low value, positive trends in the LAI at anthesis were obvious at the medium and high seeding rates $\left(\mathrm{R}_{\text {Medium seding rate }}^{2}=0.51\right.$, $\mathrm{P}>0.05 ; \mathrm{R}_{\text {High seeding rate }}^{2}=0.76, \mathrm{P}<0.05 ;$ Fig. 4a). Consequently, by excluding the extremely high value of the cultivar that

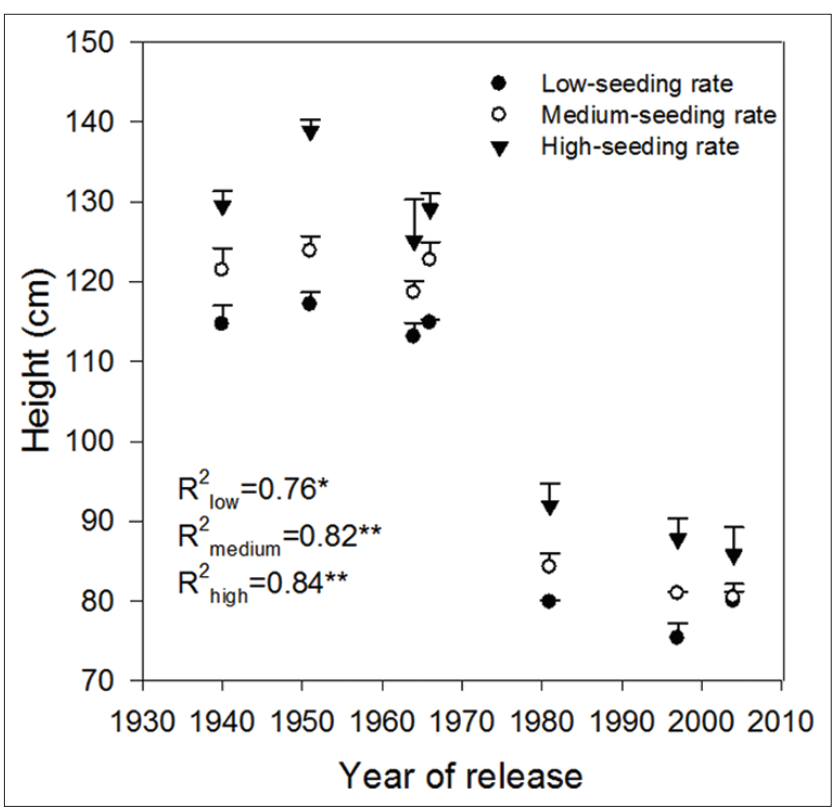

Fig 2. Plant height at maturity of the seven cultivars at different seeding rates. *Significant at $\mathrm{P}=0.05$. ${ }^{*}$ Significant at $\mathrm{P}=0.01$.

was released in 1966, a significant and negative trend was observed in the DIFN with cultivar replacement at anthesis for all three seeding rates $\left(\mathrm{R}_{\text {Low seeding rate }}^{2}=0.89\right.$, $\mathrm{P}<0.05 ; \mathrm{R}_{\text {Medium seeding rate }}^{2}=0.93, \mathrm{R}_{\text {High seeding rate }}^{2}=0.85, \mathrm{P}<0.01$; Fig. 4c).

The yield increases of modern cultivars at all seeding rates were significantly correlated with the photosynthetic trait changes at anthesis (Table 5). Previous results indicated that these yield improvements were caused by agronomic traits, especially the thousand-grain weight and harvest index (Table 4). The Pn of the flag leaf and the LAI at anthesis had significant positive influences on the thousand grain weight and harvest index at all three densities. The DIFN at anthesis was positively correlated with the TGW and yield, especially under the high seeding rate $\left(\mathrm{r}_{\mathrm{TGW}}=-0.94\right.$, $\left.\mathrm{P}<0.01 ; \mathrm{r}_{\text {Yield }}=-0.68, \mathrm{P}>0.05\right)$. 
Table 3: Yield components of the seven cultivars at different seeding rates

\begin{tabular}{|c|c|c|c|c|c|c|c|c|c|}
\hline \multirow{2}{*}{$\begin{array}{l}\text { Year of release } \\
\text { Seeding rate }\end{array}$} & \multicolumn{3}{|c|}{ Aboveground biomass $\left(\mathrm{kg} \mathrm{ha}^{-1}\right)$} & \multicolumn{3}{|c|}{ HI (\%) } & \multicolumn{3}{|c|}{ TGW (g) } \\
\hline & Low & Medium & High & Low & Medium & High & Low & Medium & High \\
\hline 1940 & 12093 & 16567 & 13710 & 29.5 & 32.2 & 27 & 37.2 & 35.4 & 35.3 \\
\hline 1951 & 13933 & 12733 & 13760 & 31.8 & 39.9 & 31.2 & 41.7 & 40.1 & 39.9 \\
\hline 1964 & 13763 & 15527 & 11253 & 43.3 & 33.3 & 31.5 & 42.1 & 41.7 & 40.5 \\
\hline 1966 & 12807 & 15443 & 11980 & 32.5 & 37.5 & 31.8 & 35.8 & 35.1 & 34.2 \\
\hline 1981 & 13200 & 17577 & 13683 & 41.1 & 40.6 & 36.4 & 42.5 & 41.7 & 40.5 \\
\hline 1997 & 15387 & 18340 & 14063 & 44 & 43.7 & 41.9 & 48.3 & 46.6 & 45.8 \\
\hline 2004 & 15037 & 16820 & 18343 & 44.2 & 48.4 & 50.8 & 45.4 & 44.7 & 42.4 \\
\hline Genetic gain (\%) & 0.29 & 0.3 & 0.37 & 0.64 & 0.52 & 0.88 & 0.34 & 0.37 & 0.31 \\
\hline $\mathrm{R}^{2}$ & $0.63^{*}$ & 0.35 & 0.32 & $0.71^{*}$ & $0.72^{*}$ & $0.93^{* *}$ & $0.57^{*}$ & $0.63^{*}$ & 0.52 \\
\hline SE & 444.7 & 690.4 & 852.5 & 2.5 & $2.1^{*}$ & 3.1 & 1.6 & 1.6 & 1.5 \\
\hline Year of release & \multicolumn{3}{|c|}{ Spike number per unit area $\left(10^{4} \mathrm{ha}^{-1}\right)$} & \multicolumn{3}{|c|}{ Grain number per spike } & \multicolumn{3}{|c|}{ Grain number per unit area $\left(10^{4} \mathrm{ha}^{-1}\right)$} \\
\hline Seeding rate & Low & Medium & High & Low & Medium & High & Low & Medium & High \\
\hline 1940 & 450.7 & 739.3 & 686.3 & 37.1 & 31.8 & 27.4 & 16804.6 & 23545.3 & 18762.7 \\
\hline 1951 & 516.7 & 659.3 & 594.3 & 30.5 & 25.9 & 22.2 & 14517.3 & 17133.1 & 13190.5 \\
\hline 1964 & 539 & 638.7 & 536.3 & 32.1 & 25.8 & 23.4 & 17382.2 & 16411.6 & 12553.3 \\
\hline 1966 & 576.7 & 742 & 688.3 & 31.8 & 21.8 & 19.5 & 183323 & 16196.8 & 13421.4 \\
\hline 1981 & 554.7 & 847 & 753 & 31.3 & 27 & 29.8 & 18170.1 & 23110.4 & 22516.1 \\
\hline 1997 & 561.7 & 748.3 & 617.3 & 35 & 24.5 & 26.1 & 19645.1 & 18375.4 & 15878.1 \\
\hline 2004 & 484 & 604.3 & 726 & 40.4 & 34.8 & 31.6 & 19451.7 & 21069.5 & 22803.5 \\
\hline Genetic gain (\%) & 0.12 & 0.04 & 0.15 & 0.18 & 0.09 & 0.36 & 0.35 & 0.05 & 0.49 \\
\hline $\mathrm{R}^{2}$ & 0.10 & 0.01 & 0.08 & 0.16 & 0.02 & 0.24 & $0.64^{*}$ & 0.01 & 0.21 \\
\hline SE & 17.2 & 31.2 & 29.2 & 1.4 & 1.7 & 1.6 & 663.4 & 1186.3 & 1658.9 \\
\hline
\end{tabular}

*Significant at $\mathrm{P}=0.05 .{ }^{*}$ Significant at $\mathrm{P}=0.01$

Table 4: Correlations between the yield and yield components at different seeding rates

\begin{tabular}{lccc}
\hline Seeding rate treatments & $\begin{array}{c}\text { Low } \\
\text { seeding } \\
\text { rate }\end{array}$ & $\begin{array}{c}\text { Medium } \\
\text { seeding } \\
\text { rate }\end{array}$ & $\begin{array}{c}\text { High } \\
\text { seeding } \\
\text { rate }\end{array}$ \\
\hline Yield and its components & 0.65 & 0.248 & 0.548 \\
Grain number per area & $0.858^{* *}$ & $0.850^{*}$ & 0.666 \\
1000-grain weight & $0.804^{* *}$ & 0.456 & $0.832^{*}$ \\
Aboveground biomass & $0.982^{* *}$ & $0.933^{* *}$ & $0.970^{* *}$ \\
Harvest index & & & \\
*Significant at $\mathrm{P}=0.05 .{ }^{* *}$ Significant at $\mathrm{P}=0.01$ & & \\
\end{tabular}

\section{DISCUSSION}

Cultivar replacement was the most important element responsible for increasing winter wheat yields, with an annual genetic gain of $0.5 \%-1 \%$ in China (Chen et al., 2003; Zhang et al., 2017), a bit lower than world average of 1.1\% (Hall and Richards, 2013). Significant genetic gains were achieved for all of the seeding rates in our study, which was consistent with former studies in this area (Chen et al, 2012) because different cultivars showed different dry matter accumulation and yield responses to the population size (Brian et al., 2011). Thus, the effects of seeding rate should be considered in cultivar breeding and genetic progress estimates.

The cultivars produced the highest yields at a medium seeding rate (Table 2), except for the cultivar released in 2004. Gooding et al. (2002) and Fang et al. (2010),
Table 5: Correlations between the yield and photosynthetic characteristics at anthesis for different seeding rates

\begin{tabular}{lcccc}
\hline Seeding rate & Pn $^{\varepsilon}$ & LAI $^{\S}$ & MTA $^{\varsigma}$ & DIFN $^{\ddagger}$ \\
\hline Low seeding rate & $0.83^{*}$ & 0.66 & -0.17 & -0.52 \\
Yield & 0.84 & $0.83^{*}$ & 0.29 & -0.60 \\
TGW & 0.69 & 0.14 & -0.33 & -0.17 \\
Grain number per area & 0.80 & $0.79^{\star}$ & 0.32 & -0.72 \\
Aboveground biomass & 0.75 & 0.54 & -0.26 & -0.39 \\
HI & & & & \\
Medium seeding rate & 0.61 & $0.85^{*}$ & 0.22 & $-0.83^{*}$ \\
Yield & 0.60 & $0.60^{*}$ & 0.30 & $-0.92^{* *}$ \\
TGW & 0.63 & 0.40 & 0.54 & -0.32 \\
Grain number per area & 0.38 & 0.55 & 0.03 & -0.54 \\
Aboveground biomass & 0.34 & 0.63 & 0.05 & -0.60 \\
HI & & & & \\
High seeding rate & $0.80^{*}$ & 0.72 & 0.38 & -0.68 \\
Yield & $0.86^{*}$ & $0.92^{\star *}$ & 0.68 & $-0.94^{* *}$ \\
TGW & 0.53 & 0.39 & 0.33 & -0.39 \\
Grain number per area & 0.69 & 0.40 & 0.31 & -0.42 \\
Aboveground biomass & 0.74 & 0.77 & 0.40 & -0.66 \\
HI & & & & \\
\hline
\end{tabular}

${ }^{*}$ Significant at $\mathrm{P}=0.05$. ${ }^{*}$ Significant at $\mathrm{P}=0.01$. $£$ Photosynthetic rate of the flag leaf. §Leaf area index. ¿Mean tilt angle. §Diffuse non-interceptance

reported that the grain yield in wheat was greatest when using a seeding rate of approximately 250 seeds $\mathrm{m}^{-2}$. According to Donald (1981), plants with a lower individual competitiveness result in a more established population. The yield CV of modern cultivars (Table 2) was lower than of the yield CVs of the older cultivars, indicating that the modern cultivars were much less 


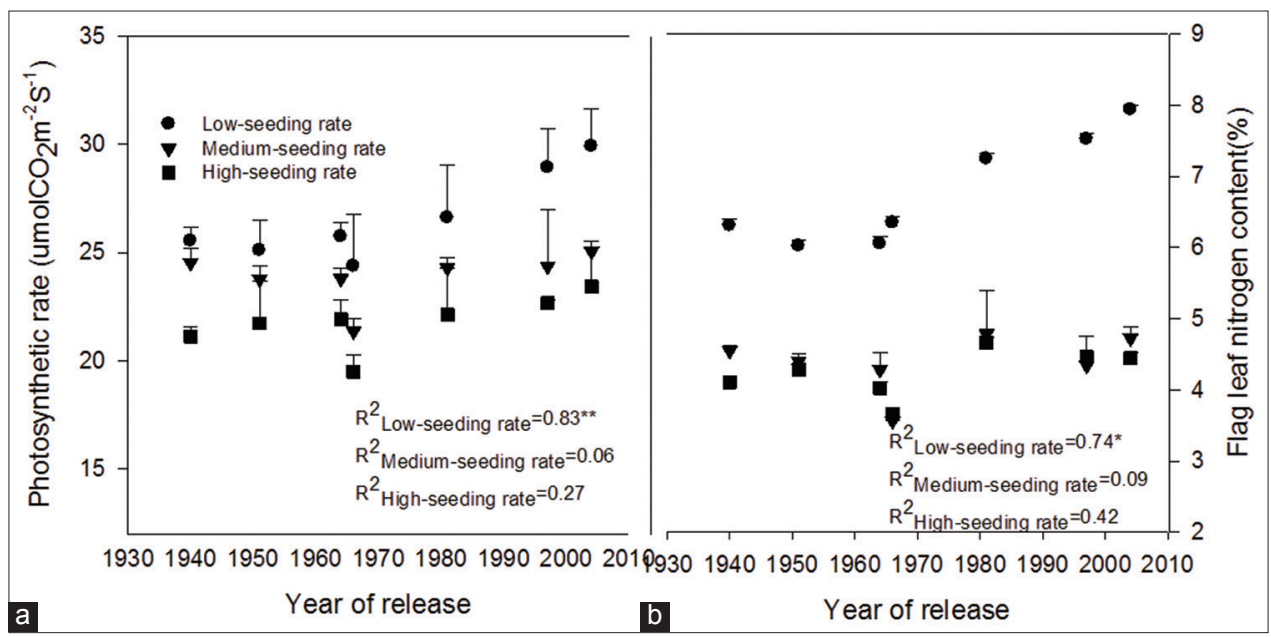

Fig 3. (a and b) Flag leaf photosynthetic rates and nitrogen contents of the seven cultivars at anthesis for different seeding rates. ${ }^{*}$ Significant at $\mathrm{P}=0.05$. ${ }^{* *}$ Significant at $\mathrm{P}=0.01$.

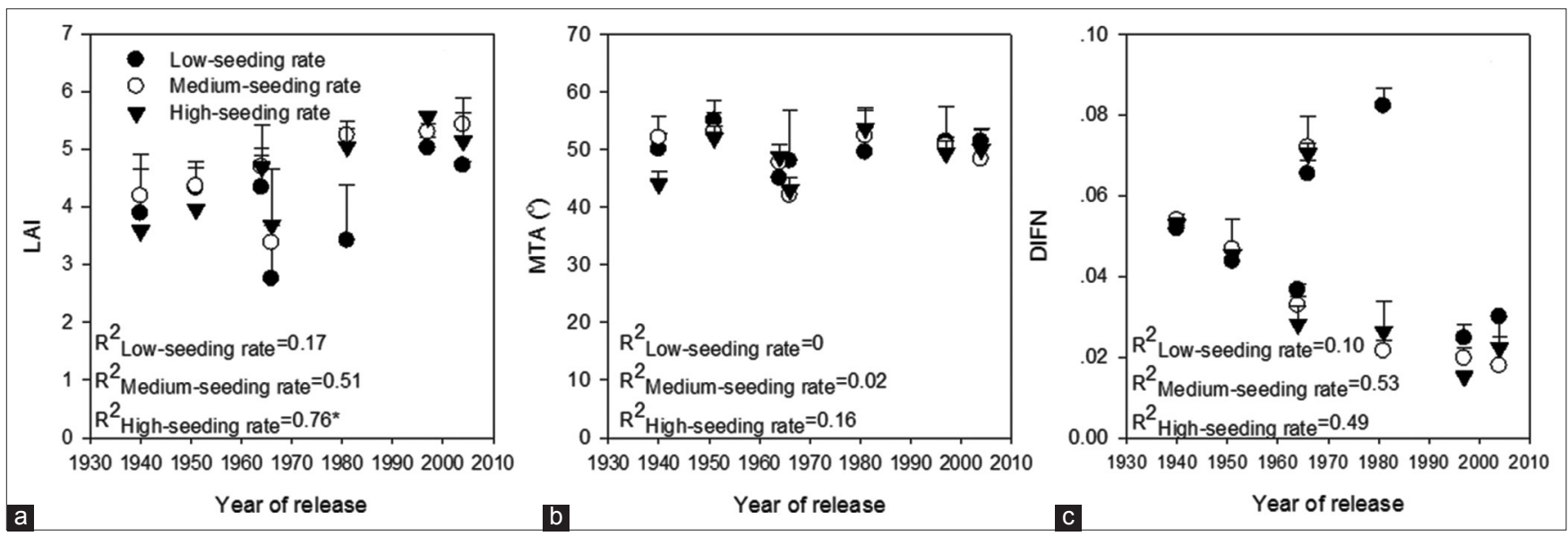

Fig 4. (a-c) Canopy characteristics (leaf area index, LAl; mean tilt angle, MTA; and diffuse non-interceptance, DIFN) of the seven cultivars at anthesis for different seeding rates. * Significant at $\mathrm{P}=0.05$.

sensitive to the seeding rate. This decreased sensitivity to seeding rate is beneficial for modern planting cultivation techniques. The cultivar that was released in 2004 was not only the highest-yielding but also the most unique because it obtained the highest yield under a seeding rate of 350 seeds $\mathrm{m}^{-2}$ (Table 3). This result suggested the benefits of a further increase in the seeding rate for modern cultivars on the Loess Plateau.

The plant height on the Loess Plateau after the 1980s decreased to approximately $70 \mathrm{~cm}$ (Fig. 2), which was lower than the requirement for grain yield (Chen et al., 2003), with shorter plants affecting the population quality and reducing the grain yield. Based on the listed yield components (Table 3) and their relationships with grain yield (Table 4), the HI and TGW increases can be considered as key factors for yield improvements on the Loess Plateau, regardless of the seeding rate. The grain number per unit area showed no significant improvement for any seeding rate and contributed less to the yield production. Aisawi et al. (2015) and Donmez et al. (2001) got similar results. BrancourtHulmel et al. (2003) and Sayre et al. (1997), confirmed that the wheat grain yield is more strongly related to the kernel number per unit ground area than the kernel weight.

Significant increases resulting from cultivar replacement were observed in the aboveground biomass in Australia and Brazilian (Perry and D'Antuono, 1989; Beche et al., 2014), but no changes were found in England (Austin et al., 1980) or France (Brancourt-Hulmel et al., 2003). In this study, the aboveground biomass significantly increased and was only correlated with yield improvements at a low seeding rate. This result indicated that the cultivars with greater production capacities could have outstanding yields when the population size is small.

It is widely acknowledged that a large part of grain saccharides are derived from photosynthates in the leaves especially the 
flag leaf (Condon et al., 2004; Pierre et al., 2015). Thus, understanding changes in the photosynthetic traits of new cultivars provides important information for genetic improvement (Richards, 2000). The Pn of the flag leaves at anthesis significantly increased with cultivar replacement for each seeding rate considered in our study (Fig. 3a). In addition, the relevant contributions of the Pn to TGW and yield were positive and significant (Table 5), corresponding with the results of Reynolds et al. (2000) and Tian et al. (2011).

Canopy photosynthesis should be improved to increase cereal grain yields (Zhu et al., 2010). The LAI, MTA, and DIFN together were all effective measurements for evaluating light absorption (Lanning et al., 1997). The LAI of the modern cultivars in this study was greater than the older cultivars at the medium and high seeding rates (Fig. 4a), and the LAI at anthesis was always positively correlated with those the TGW and yield (Table 5). Wang et al. (2016) and Condon et al. (2004) also reported that rapid leaf area growth is a beneficial trait in benign environments.

Genotypes with upright leaves are considered less competitive than those with more horizontal leaf orientations (Huel and Hucl, 1996). In this study, the MTA at anthesis showed no obvious change over the decades (Fig. 4b) and was not correlation with the yield (Table 5) in any treatment. The leaf directions were nearly consistent with cultivar replacement. However, the DIFN at anthesis generally decreased with cultivar replacement at all seeding rates (Fig. 4c). These results correspond with those of Lanning et al. (1997), who considered that less light generally penetrates between the rows of taller varieties. The DIFN values obtained on the Loess Plateau were below that previously reported by Lanning et al. (1997) and Wang et al. (2009), and suggest that wheat breeding in this region could be more efficient for transmitting light. Based on the significant negative correlations between the DIFN at anthesis and the yields in every treatment (Table 5), it was concluded that the modern cultivars possessed higher LAI and lower DIFN values at anthesis, which was beneficial for light interception and use and resulted in greater TGWs and yield increases. Furthermore, the LAI values of wheat at anthesis on the Loess Plateau (Fig. 4) were just below or similar to the critical LAI value of 6 (Parry et al., 2011) and the MTA values of the cultivars were stable. Thus, it was concluded that the decrease in the DIFN at anthesis mainly resulted from the increased LAI. However, additional studies are needed.

\section{CONCLUSIONS}

Significant genetic improvements of dryland winter wheat on the Loess Plateau were achieved with 100, 250 and
350 seeds $\mathrm{m}^{-2}$. Modern cultivars were less sensitive to seeding rate and were favorable for modern cultivation techniques of high population size. For further increases in grain yield, improvement in the HI and TGW would be beneficial. In addition, higher LAI and lower DIFN at anthesis are more efficient for light absorption and should be further considered.

\section{ACKNOWLEDGMENTS}

This work was supported by the National Sciencetechnology Support Plan Projects (2015BAD22B01) and National Science Foundation(31500320).

\section{Author's contributions}

Suiqi Zhang: Design, formulation and supervision of experiment with writing. Yingying Sun: Carried out the project and drafted the manuscript. Xiaojuan Yan and Nan Wang: Participated in data analysis. All authors read and approved the final manuscript.

\section{REFERENCES}

Aisawi, K. A. B., M. P. Reynolds, R. P. Singh and M. J. Foulkes. 2015. The physiological basis of the genetic progress in yield potential of CIMMYT spring wheat cultivars from 1966 to 2009. Crop Sci. 55(4): 484-489.

Anderson, W. K and J. Barclay. 1991. Evidence for differences between three wheat cultivars in yield response to plant population. Aust. J. Agric. Res. 42: 701-713.

Arduini, I., A. Masoni, L. Ercoli and M. Mariotti. 2006. Grain yield, and dry matter and nitrogen accumulation and remobilization in durum wheat as affected by variety and seeding rate. Eur. J. Agron. 25: 309-318.

Austin, R. B., J. Bingham, R. D. Blackwell, L. T. Evans, M. A. Ford, C. L. Morgan and M. Taylor. 1980. Genetic improvements in winter wheat yields since 1900 and associated physiological changes. J. Agric. Sci. 94: 675-689.

Beche, E., G. Benin, C. L. da Silva, L. B. Munaro and J. A. Marchese. 2014. Genetic gain in yield and changes associated with physiological traits in Brazilian wheat during the $20^{\text {th }}$ century. Eur. J. Agron. 61: 49-59.

Black, A. L and J. K. Aase. 1982. Yield component comparisons between USA and USSR winter wheat cultivars. Agron. J. 74: 436-441.

Brancourt-Hulmel, M., G. Doussinault, C. Lecomte, P. Bérard, B. L. Buanec and M. Trottet. 2003. Genetic improvement of agronomic traits of winter wheat cultivars released in France from 1946 to 1992. Crop Sci. 43: 37-45.

Brian, B. L., H. A. Cárcamo, R. C. Yang and D. M. Spaner. 2011. Integrating spring wheat sowing density with variety selection to manage wheat stem sawfly. Agron. J. 103: 1755-1764.

Carr, P. M., R. D. Horsley and W. W. Poland. 2003. Tillage and seeding rate effects on wheat cultivars. I. Grain production. Crop Sci. 43: 202-209.

Chen, X., M. D. Hao, J. J. Xu and Y. L. Zhu. 2012. Effect of drought stress on photosynthesis characteristics in flag leaf of wheat cultivars in different years in the central Shaanxi plain (In Chinese, 
with English abstract). Agric. Res. Arid Area. 30: 159-163, 169.

Chen, X., Q. S. Zhuang and W. Q. Zhang. 2003. Introduction of Chinese wheat improvement and pedigree analysis (In Chinese). In: Zhuang, Q. S (Ed.), Chinese Wheat Improvement and Pedigree Analysis, China Agriculture Press, Beijing, pp. 3-5.

Condon, A. G., R. A. Richards, G. J. Rebetzke and G. D. Farquhar. 2004. Breeding for high water-use efficiency. J. Exp. Bot. 55: 2447-2460.

Donald, C. M. 1981. Competitive plants, communal plants, and yield in wheat crops. In: Evans, L. T and W. J. Peacock (Ed.), Wheat Science-Today and Tomorrow, Cambridge University Press, Cambridge, pp. 223-247.

Donmez, E., R. G. Sears, J. P. Shroyer and G. M. Paulsen. 2001. Genetic gain in yield attributes of winter wheat in the Great Plains. Crop Sci. 41: 1412-1419.

Easson, D. L., E. M. White and S. J. Pickles. 1993. The effects of weather, seed rate and cultivar on lodging and yield in winter wheat. J. Agric. Sci. 121: 145-156.

Fang, Y., B. C. Xu, N. C. Turner and F. M. Li. 2010. Grain yield, dry matter accumulation and remobilization, and root respiration in winter wheat as affected by seeding rate and root pruning. Eur. J. Agron. 33: 257-266.

Fischer, R. A. 1981. Optimizing the use of water and nitrogen through breeding of crops. Plant Soil. 58: 249-278.

Fischer, R. A. and R. Maurer. 1978. Drought resistance in spring wheat cultivars. Part 1: Grain yield response. Aust. J. Agric. Res. 29: 897-912.

Fischer, R. A., R. Maurer and G. O. Edmeades. 2010. Breeding and cereal yield progress. Crop Sci. 50: 85-98.

Gent, M. P. N and R. K. Kiyomoto. 1985. Comparison of canopy and flag leaf net carbon dioxide exchange of 1920 and 1977 New York winter wheats. Crop Sci. 25: 81-86.

Gooding, M. J., A. Pinyosinwat and R. H. Ellis. 2002. Responses of wheat grain yield and quality to seed rate. J. Agric. Sci. 138: 317-331.

Hall, J.A and R. A. Richards. 2013. Prognosis for genetic improvement of yield potential and water-limited yield of major grain crops. Field Crops Res. 143: 18-33.

Huel, D. G and P. Hucl. 1996. Genotypic variation for competitive ability in spring wheat. Plant Breed. 115: 325-329.

Marshall, G. C and H. W. Ohm. 1987. Yield responses of 16 winter wheat cultivars to row spacing and seeding rate. Agron. J. 79: 1027-1030.

Maydup, M. L., M. Antonietta, J. J. Guiamet and E. A. Tambussi. 2012. The contribution of green parts of the ear to grain filling in old and modern cultivars of bread wheat (Triticum aestivum L.): Evidence for genetic gains over the past century. Field Crops Res. 134: 208-215.

McCaig, T. N and R. M. DePauw. 1995. Breeding hard red spring wheat in western Canada: Historical trends in yield and related variables. Can. J. Plant Sci. 75: 387-393.

Ortiz-Monasterio, R., K. D. Sayre, S. Rajaram and M. McMahon. 1997. Genetic progress in wheat yield and nitrogen use efficiency under four nitrogen rates. Crop Sci. 37: 898-904.

Parry, M. A. J., M. Reynolds, M. E. Salvucci, C. Raines, P. J. Andraloj, X. G. Zhu, G. D. Price, A. G. Condon and R. T. Furbank. 2011.
Raising yield potential of wheat. II. Increasing photosynthetic capacity and efficiency. J. Exp. Bot. 62: 453-467.

Perry, M. W and M. F. D'Antuono. 1989. Yield improvement and associated characteristics of some Australian spring wheat cultivars introduced between 1860 and 1982. Crop Pasture Sci. 40: 457-472.

Pierre, B., B. Marie-Odile, C. François and G. David. 2015. Identifying traits leading to tolerance of wheat to Septoria tritici blotch. Field Crops Res. 180: 176-185.

Potgieter, B. A., D. B. Lobell, G. L. Hammer, D. R. Jordan, P. Davis and J. Brider. 2016. Yield trends under varying environmental conditions for sorghum and wheat across Australia. Agric. For. Meteorol. 228-229: 276-285.

Reynolds, M. P., B. M. I. Delgado, M. Gutiérrez-Rodríguez and A. Larqué-Saavedra. 2000. Photosynthesis of wheat in a warm, irrigated environment. I: Genetic diversity and crop productivity. Field Crops Res. 66: 37-50.

Richards, R. A. 2000. Selectable traits to increase crop photosynthesis and yield of grain crops. J. Exp. Bot. 51: 447-458.

Sayre, K. D., S. Rajaram and R. A. Fischer. 1997. Yield potential progress in short bread wheats in Northwest Mexico. Crop Sci. 37: $36-42$.

Rothamsted Experimental Station. 1974. Rothamsted Experimental Station, Report for 1973, Hertfordshire, Rothamsted Experimental Station, Harpenden.

Tian, Z. W., Q. Jing, T. B. Dai, D. Jiang and W. X. Cao. 2011. Effects of genetic improvements on grain yield and agronomic traits of winter wheat in the Yangtze River Basin of China. Field Crops Res. 124: 417-425.

Wang, Y. Q., W. S. Xi, Z. M. Wang, B. Wang, X. X. Xu, M. K. Han, S. L. Zhou and Y. H. Zhang. 2016. Contribution of ear photosynthesis to grain yield under rainfed and irrigation conditions for winter wheat cultivars released in the past 30 years in North China Plain. J. Intergr. Agric. 15: 2247-2256.

Wang, Y. T., Y. Yi, J. X. Zhang, L. B. Hou, J. T. Kang and X. K. Dong. 2009. Effects of irrigation on winter wheat photosynthetic character and canopy structure (In Chinese, with English abstract). Agric. Res. Arid Areas. 27: 63-66, 72.

Zhang, X. Y., W. L. Qin, S. Y. Chen, L. W. Shao and H. Y. Sun. 2017. Responses of yield and WUE of winter wheat to water stress during the past three decades-A case study in the North China Plain. Agric. Water Manag. 179: 47-54.

Zhang, Y., M. D. Hao and Y. H. Pang. 2008. Study on the grain filling characteristic of the succession of wheat cultivars in the gully areas of the Loess Plateau (In Chinese, with English abstract). J. Triticeae Crop. 28: 1058-1062.

Zhang, Y., M. D. Hao, Y. H. Pang and H. L. Fan. 2009. Study on evolution of species traits and quality characters of Changwu brand in dryland of the Loess Plateau(In Chinese, with English abstract). Acta Agric. Boreali Occidentalis Sin. 18: 65-70.

Zheng, T. C., X. K. Zhang, G. H. Yin, L. N. Wang, Y. L. Han, L. Chen, F. Huang, J. W. Tang, X. C. Xia and Z. H. He. 2011. Genetic gains in grain yield, net photosynthesis and stomatal conductance achieved in Henan Province of China between 1981 and 2008. Field Crops Res. 122: 225-233.

Zhu, X. G., S. P. Long and D. R. Ort. 2010. Improving photosynthetic efficiency for greater yield. Annu. Rev. Plant Biol. 61: 235-261. 